\title{
ARTÍCULOS
}

\section{OCASIO ALONSO, UN MARINERO EN LA PRIMERA VUELTA AL MUNDO: INCIDENCIAS Y VICISITUDES DE UN SUPERVIVIENTE.}

\author{
Francisco Luis Jiménez Abollado \\ Universidad Autónoma del Estado de Hidalgo \\ fjimenez@uaeh.edu.mx
}

Resumen: En este trabajo se pretende rescatar a uno de los supervivientes del primer viaje que dio la vuelta al mundo en la expedición Magallanes-Elcano, Ocasio Alonso, natural de Bollullos del Condado, en la actual provincia de Huelva. Gracias al expediente "Probanza de la posesión del Maluco. Badajoz, 1524", sito en la sección Patronato del Archivo General de Indias, podemos acceder a su testimonio como integrante de la citada expedición. El documento pretende aclarar la posesión de las islas del Maluco durante el conflicto castellano-portugués por el control de los dominios de la Especiería. Ocasio Alonso se convirtió en uno de los testigos presentados por la Corona imperial española. Además de este expediente, que nos va a servir para conocer al personaje y su participación en este hito histórico, lo seguiremos también a través de otras peripecias acaecidas durante la travesía y que han quedado recogidas en crónicas y trabajos realizados para ensalzar y dar a conocer la gesta circunnavegadora.

Palabras clave: Ocasio Alonso, primera vuelta al mundo, Magallanes, Elcano, Molucas, Especiería.

Tittle: OCASIO ALONSO, A SAILOR ON THE FIRST ROUND THE WORLD: INCIDENCES AND VICISSITUDES OF A SURVIVOR.

Abstract: This work aims to rescue one of the survivors of the first trip that went around the world in the Magallanes-Elcano expedition, Ocasio Alonso, a native of Bollullos del Condado, in the current province of Huelva. Thanks to the file "Probanza de la posesión del Maluco. Badajoz, 1524", located in the section Patronato of the General Archive of the Indies, we can access your testimony as a member of that expedition. The document aims to clarify the possession of the Maluco Islands during the Castilian-Portuguese conflict by controlling the domains of the Especiería. Ocasio Alonso became one of the witnesses presented by the Spanish imperial crown. In addition to this transcript which will serve us to meet the character and his participation in this historic milestone, we will also follow him through other adventures that occurred during the crossing and that have been collected in chronicles and works carried out to praise and publicize the circumnavigating deed.

Keywords: Ocasio Alonso, first round the world, Magallanes, Elcano, Molucas, Especieria.

Cómo citar este artículo: JIMÉNEZ ABOLLADO, Francisco Luis. Ocasio Alonso, un marinero en la primera vuelta al mundo: incidencias y vicisitudes de un superviviente. Naveg@mérica. Revista electrónica editada por la Asociación Española de Americanistas [en línea]. 2019, n. 23. Disponible en: <http://revistas.um.es/navegamerica>. [Consulta: Fecha de consulta]. ISSN 1989-211X. 


\section{Introducción}

Escribimos estas palabras cuando se están celebrando los 500 años de un hito histórico que no se buscaba realizar per se, pero las circunstancias de las fortunas lo llevaron a convertirse en "la vuelta a toda la redondez del mundo, y [que] yendo para el occidente hayamos regresado por el oriente"1. La realización de esta gesta marítima no fue producto de una simple apuesta de unos marinos, con la ayuda efectiva de la Corona castellana, por llevar a cabo un reto hasta entonces inimaginable. El interés de las monarquías ibéricas por hacerse con el dominio de los mares del Índico y del Pacífico se centraba en controlar los productos que en el entorno de las islas Molucas, desde épocas pasadas, comerciantes árabes y chinos introducían en la medieval Europa como verdaderas mercancías de lujo: las especias.

Desde los últimos años del siglo XV, coincidiendo con los periplos colombinos, asistimos a una enconada lucha por el control de las rutas marítimas entre Castilla y Portugal. Esta situación desembocó en 1494 cuando ambas naciones ratificaron en el Tratado de Tordesillas la división territorial del mundo en un hemisferio oriental portugués y otro occidental español, trasladándose la línea de demarcación a 370 leguas al Oeste de las islas de Cabo Verde. Castilla en 1492 quería alcanzar las ansiadas Indias por occidente, en busca de las especias, pero topó con otras tierras desconocidas para los europeos ${ }^{2}$. Portugal, por su parte, había conseguido en 1487 doblar la punta meridional de África, el cabo de Buena Esperanza; en 1498, Vasco de Gama abre la vía marítima a la India, y entre 1505 y 1515 los portugueses crearían el primer eslabón del Imperio portugués en las tierras del Indico (Goa, Ceilán, Malaca, India insular) ${ }^{3}$. La respuesta de la Corona española no se haría esperar en su intento de controlar también dichas tierras, financiando en 1519 la expedición de Hernando de Magallanes ${ }^{4}$. Las crecientes dudas sobre si estas posesiones del Pacífico pertenecían a Castilla o Portugal llevó a Carlos I en 1524 a reunir la Junta de Badajoz, para tratar de dilucidar el asunto. A ella asistieron científicos, expertos marinos y los pocos supervivientes de la expedición de Magallanes, entre ellos nuestro protagonista.

En este trabajo vamos a centrarnos en la figura de Ocasio Alonso, "natural de

\footnotetext{
${ }^{1}$ El libro que trajo la nao Victoria de las amistades que hicieron con los reyes del Maluco, Archivo General de Indias (en adelante, AGI), Indiferente General, 1528, N.1.

2 Para un análisis exhaustivo del Tratado de Tordesillas y sus implicaciones, véanse: RUMEU DE ARMAS, A. El Tratado de Tordesillas. Madrid: Editorial Mapfre, 1992; MORALES PADRÓN, Francisco. El Tratado de Tordesillas. En: Teoría y Leyes de la conquista. Sevilla: Universidad de Sevilla, 2008, pp. 189-213.

3 Sobre los primeros descubrimientos y expediciones portuguesas, véanse: PÉREZ-EMBID, F. Los descubrimientos del Atlántico y la rivalidad castellano-portuguesa hasta el Tratado de Tordesillas. Sevilla: EEHA-CSIC, 1948; DA FONSECA, L. A. The discoveries and the formation of the Atlantic Ocean: 14th century - 16th century. Lisbon: Comissão Nacional para as Comemorações dos Descobrimentos Portugueses, 1999; FERNÁNDEZ-ARMESTO, F. Los conquistadores del horizonte. Una historia global de la exploración. Madrid: Ariel, 2012, pp. 231-347.

${ }^{4}$ Salvador Bernabeu ha realizado recientemente un excelente estudio en torno a la figura de Hernando de Magallanes describiendo su itinerario vital; BERNABEU, S. Magallanes: retrato de un hombre. En: YUSTE, C. y PINZÓN RíOS, G. (coords.). A 500 años del hallazgo del Pacífico. La presencia novohispana en el Mar del Sur. México: IIH-UNAM, 2016, pp. 21-54.
} 
Bollullos", como reza en la Probanza sobre la posesión del Maluco que se le realizó en Badajoz ${ }^{5}$; un marinero del que sin embargo disponemos documentación histórica y testimonios procedentes de diferentes crónicas y estudios. El objetivo propuesto es enmarcar su figura en los hechos acaecidos durante la travesía, muchos de ellos conocidos, usando además la información generada por el marinero. Sin caer en el género biográfico clásico, tan denostado por lineal y positivista por las diferentes escuelas del siglo XX, desde el marxismo, pasando por los Annales, hasta la microhistoria italiana, convenimos con Carlos Aguirre Rojas cuando señala que el historiador debe valerse del género biográfico para estudiar al individuo en su medio, época y contexto ${ }^{6}$. Así, ahondaremos en este personaje encajándolo en los momentos claves de esta expedición, desde su enrolamiento en la nao Santiago, su protagonismo durante el paso por el bautizado Estrecho de Todos los Santos, más tarde de Magallanes, la estancia en el Maluco gracias a la Probanza sobre la posesión del Maluco, su retención por los portugueses en Cabo Verde en el viaje de vuelta de la nao Victoria a España y la obtención de las retribuciones y premios monetarios. En definitiva, este trabajo responde al rescate de un marinero ignorado por los especialistas en esta gesta y no estudiado hasta el momento, además de un superviviente de la misma.

\section{Primeros datos de Ocasio Alonso: filiación y marinero}

Ocasio Alonso nació en 1488 en la villa de Bollullos, enclavada en el señorío del ducado de Medina Sidonia, junto al Condado de Niebla, cuando el proyecto colombino estaba aún en ciernes. Su juventud se desarrolló en la denominada "plataforma atlántica", en el Sur del reino de Castilla, que abarcaba desde la bahía gaditana, las comarcas del Condado de Niebla y las que se extendían desde Palos y Moguer a Ayamonte, convertidas desde mediados del siglo XV en la mejor escuela de formación de buena parte de los marineros y tripulantes de la después intitulada "Carrera de Indias"7. Alonso fue reclutado en 1519 para incorporarse a la expedición de Hernando de Magallanes. Tenía por entonces 30 años, estaba casado en Bollullos y ejercía en Sevilla el oficio de marinero, posiblemente curtido en experiencias navales en las cercanas costas de África y las Islas Canarias. El mismo Antonio Pigafetta, que acompañó a la expedición, superviviente de la misma, y escribió a su vuelta la Relazioni in torno al primo viaggio di circumnavigazione. Notizia del Mondo Nuevo con le figure dei paesi scorpeti, señala que para alistarse a la misma tuvo que partir "con muchas cartas de recomendación desde la ciudad de Barcelona, donde paraba". . Desconocemos si Alonso tuvo que recurrir a estas

\footnotetext{
${ }^{5}$ Probanza sobre la posesión del Maluco en Badajoz, 1524, AGI, Patronato, 48, R. 15.

${ }^{6}$ AGUIRRE ROJAS, C. A. La biografía como género historiográfico. Algunas reflexiones sobre sus posibilidades actuales. En: AGUIRRE ROJAS, C. A. Itinerarios de la historiografía del siglo XX. De los diferentes marxismos a los varios Annales. La Habana: Centro de Investigación y desarrollo de la cultura cubana Juan Marinello, 1999, pp. 107-108. Además, pueden consultarse los trabajos de DOSSE, F. El arte de la biografía. México: Universidad Iberoamericana, 2007 y LOAIZA CANO, G. EI recurso biográfico. Historia crítica. 2004, n. 24, pp. 221-238.

${ }^{7}$ Al respecto, véase, MENA GARCÍA, C. El descubrimiento y la plataforma andaluza. La aportación onubense. En: Actas de las Jornadas de Historia sobre el Descubrimiento de América. Tomo II. Huelva: Universidad Internacional de Andalucía, 2011, pp. 43-71.

8 PIGAFETTA, A. Primer viaje en torno del Globo (versión castellana de Federico Ruiz Morcuende). Madrid: Calpe, 1922, p. 36.
} 
cartas, pero en el caso de Pigafetta le valió para que Magallanes lo subiera a bordo de su nao como sobresaliente.

Ocasio Alonso se embarcó en la nao Santiago, que iba al mando del capitán Juan Rodríguez Serrano. En la relación de paga y sueldos de marineros y grumetes de dicha nao, aparece nominado nuestro personaje como "Bocacio Alfonso", natural de Bollullos, "hijo de Diego Alonso de los Lagares, marido de Teresa Hernández". El sueldo que tenía asignado, como marinero, era de 1.200 maravedíes mensuales, que empezaron a cobrar desde que las cinco naos estaban prestas en Sanlúcar de Barrameda, a mediados del mes de agosto de 1519. Como muchos integrantes de la tripulación, Alonso recibió por adelantado dinero; en su caso fueron cuatro meses ${ }^{9}$.

La armada confeccionada por Hernando de Magallanes, de acuerdo con Antonio de Herrera, salió "de Sevilla, 10 días de agosto de este año [1519] en demanda de las islas de los Malucos, y la primera tierra que tomaron, fue la isla de Tenerife en las Canarias"10, donde estuvieron hasta principios de octubre. Después de poner rumbo al Suroeste y algunas discusiones con pilotos de otras naves por el derrotero que tomaba la nao capitana, la expedición llegó el 13 de diciembre a "una bahía muy grande que llamaban los portugueses en la costa del Brasil, la bahía de Género..." ", donde pasaron el día de Navidad. Desde aquí empezaron a navegar costeando el continente, alcanzando el 14 de enero el río de la Plata, donde estuvieron una semana recorriendo su bahía ${ }^{12}$. Siguiendo el derrotero Sur-Suroeste, con la costa a estribor, el objetivo de la expedición era encontrar cuanto antes el estrecho o paso que la encaminase a las Molucas.

Las dificultades en el abastecimiento a más de dos centenares de navegantes, el clima riguroso y que el estrecho no se presentaba provocaron el descontento en un sector de la tripulación cuando llegaron en abril al río de San Julián y su bahía, donde Magallanes proponía como buen lugar para invernar. Los capitanes de las naos Victoria y Concepción, Luis de Mendoza y Gaspar de Quesada, y el que fuera de la San Antonio, Juan de Cartagena, que con anterioridad fue sustituido por el primo del capitán general, Álvaro de la Mezquita, se amotinaron con parte de la tripulación. Hernando de Magallanes, con rapidez, sofocó el levantamiento ordenando matar, de acuerdo al poder que tenía para esos sumarios, a los cabecillas, Mendoza y Quesada, mientras que Juan de Cartagena y un clérigo que también fue partícipe del motín, fueron sentenciados a quedarse en tierra cuando la expedición reiniciara su navegación ${ }^{13}$.

Juan Rodríguez Serrano, capitán de la nao Santiago, donde Ocasio Alonso servía de marinero, estuvo al margen de la revuelta y se mantuvo fiel a Magallanes. El capitán general portugués mandó a Serrano "que fuese por luego de costa, a descubrir si había estrecho, y que si en ciertas leguas no le hallase, que se

\footnotetext{
${ }^{9}$ Relación de expedicionarios que fueron en el viaje a la Especiería, sus procedencias, cargos y sueldos, agosto de 1519. AGI, Contratación, 5090, L.4, f. 51r.

${ }^{10}$ HERRERA, A. de. Historia General de los hechos de los castellanos en las islas y tierra firme del Mar Oceáno. Década Segunda. Madrid: Imprenta Real, 1601, p. 131.

${ }^{11}$ Ibídem, p. 132.

12 Ibídem, pp. 294-295.

${ }^{13}$ Ibídem, pp.297-300.
} 
volviese". Navegaron 20 leguas y toparon con un río que nominaron Santa Cruz, por la festividad del día, donde estuvieron seis días pescando y cazando lobos marinos. En un intento de seguir avanzando, la nao de Ocasio Alonso topó con un fuerte temporal que rompió todas sus velas, la hizo innavegable, quedando inutilizada y perdiendo toda la carga. Afortunadamente, los 37 miembros de la tripulación pudieron llegar con muchas dificultades a la costa. La contrariedad era volver a la bahía de San Julián donde se encontraba el resto de la armada y decidieron, después de seis días, subsistiendo a base de mariscos y yerbas, que dos personas fueran a buscar ayuda, atravesando el río Santa Cruz en una balsa. Después de 11 días por mar y tierra lograron llegar a la bahía, "tan desmejorados, que no los conocían". Hernando de Magallanes envió una expedición terrestre de veinte hombres para rescatar a los restantes, que se complicó cuando hubo que salvar en balsa el río Santa Cruz. Una vez reunidos todos en San Julián se repartió a la tripulación de la desaparecida nao Santiago en las restantes embarcaciones. Juan Rodríguez Serrano fue nombrado capitán de la Concepción, mientras que Ocasio Alonso fue traspasado a la nao Victoria ${ }^{14}$.

\section{Ocasio Alonso y su protagonismo en el paso del Estrecho}

Después de cinco meses cobijada en la bahía de San Julián, la armada de Hernando de Magallanes, a fines de agosto de 1520, ahora con cuatro naos, salió a la mar con destino al río de Santa Cruz, que ya descubriera y nominara Juan Rodríguez Serrano. Allí permanecieron hasta mediados de octubre, donde hicieron gran cantidad de pesca. Señala Herrera que siguieron costeando hasta topar el 21 de octubre con un cabo, que llamaron "de las Vírgenes", que entraba en una gran boca, y ello animó a Magallanes a enviar a la Concepción y la San Antonio a explorar por cinco días el interior de esa cala, mientras él esperaba las noticias con la Trinidad y la Victoria, pues creía que no se trataba de una bahía ${ }^{15}$.

De acuerdo con Pigafetta, las naos exploradoras recorrieron el canal "y se encontraron en otra bahía donde prosiguieron su ruta hasta que descubrieron otro estrecho, del que pasaron a otra bahía mucho más grande que las precedentes"16. Cuando observaron que continuaba el canal regresaron a la bocana donde les esperaba Magallanes, y éste no puso en tela de juicio que se hallaba en el estrecho que iba a llevar a su armada al Mar del Sur y, en consecuencia, a las islas del Maluco. Así, la flota al completo embocó el estrecho avanzando más de lo que hicieron las naves de reconocimiento con anterioridad, atravesando el Paso Ancho, o segunda angostura del estrecho, hasta divisar tres islas, la mayor, actual Isabel, y dos menores, que denominaron Islas de los Pájaros, por la gran cantidad de aves que allí atisbaron ${ }^{17}$. Hernando de Magallanes quiso organizar las pautas a seguir a partir de este momento, que consideraba clave en la expedición, y celebró una junta de capitanes, pilotos y gente principal de las cuatro embarcaciones donde se externaron distintas posiciones. Estaban los partidarios de regresar a Castilla por

\footnotetext{
14 Ibídem, pp. 299-300.

${ }^{15}$ Ibídem, pp. 301-302; PIGAFETTA, A. Primer viaje en torno del Globo. Op. cit., pp. 62-63.

16 Ibídem, pp. 63-64.

17 MARTINIC B., M. Una travesía memorable. Hallazgo y navegación del Estrecho de Magallanes (21 octubre-28 noviembre 1520). Chile: Talleres La Prensa Austral, 2016, p. 120.
} 
falta de provisiones, argumentando el conocimiento probado del camino a seguir hasta salir al Mar del Sur que debiera llevar a las Molucas, para organizar otra expedición más sólida y experimentada. Esta era la opinión del portugués Esteban Gómez, piloto de la nao San Antonio, y rival declarado de Magallanes. Sin embargo, éste, según Herrera, "con semblante muy compuesto dijo que aunque supiese comer los cueros de las vacas con que las entenas iban aforradas, había de pasar adelante y descubrir lo que había prometido al emperador"18. La decisión estaba tomada y esta reunión sólo sirvió para conocer las nuevas divergencias internas.

La expedición prosiguió su navegación. Como era 1 de noviembre la fecha de estas acciones, se le dio a este lugar el nombre de Canal de Todos los Santos. y observaron que el mar, en la ruta que llevaban, se abría al Sureste, por lo cual el capitán general ordenó dividir la expedición: mientras que la Trinidad y la Victoria siguieron la ruta marcada hacia el Suroeste, la Concepción y la San Antonio, inspeccionaron la citada apertura en el Sureste, quedando en reunirse al cabo de cuatro días. Una mala sincronización de los tiempos de espera y el lugar de reunión de las naos después del reconocimiento pudo ser la causa aprovechada por el piloto de la San Antonio, Esteban Gómez, para abandonar la armada y navegar en sentido contrario con destino a la península Ibérica. Su descontento previo con Magallanes, al opinar que la falta de víveres iba a acabar con la expedición, y la disputa con el primo de éste y capitán de la nao, Álvaro de la Mezquita, fueron claves para la toma de esta decisión que dejó a la expedición con tres naves ${ }^{19}$. La Concepción, separada con antelación de la San Antonio, siguió con la ruta fijada hasta el fondo de la bahía confirmando la inexistencia de salida al mar y terminada su labor debió salir en busca de las naos Trinidad y Victoria como se estipuló.

Mientras tanto, Magallanes, al mando de la Trinidad y la Victoria, se adentró por el derrotero señalado, rumbo Suroeste, entre el 4 y el 6 de noviembre. Estuvo un día navegando entre un paisaje muy distinto a las llanuras desoladas de la entrada en el estrecho. Montañas, árboles hasta la orilla y nieve en las alturas adornaban el trayecto; además de conseguir "gran pesquería de sardinas y sábalos,... agua y leña, tan olorosa cuando se quemaba, que con ella se recibía gran consuelo", como describió Herrera Pigafetta ${ }^{20}$, testigo directo de esta travesía, señala que denominaron a este paraje, donde pasaron cuatro días, "río de las Sardinas". Mientras esperaron en este lugar a la San Antonio y la Concepción, "se envió una chalupa muy bien equipada para que reconociese el cabo de este canal que desembocaría en otro mar". Los marineros volvieron, según Pigafetta, al tercer día con la noticia que habían divisado el cabo en el que terminaba el estrecho y se entraba al océano ${ }^{21}$. Y es aquí, en este espacio de aparente remanso y tranquilidad, sin conocer aún estos navegantes que la nao San Antonio enfilaba el camino de vuelta hacia el puerto de las Muelas en Sevilla, donde entró en acción Ocasio Alonso, ahora marinero de la nao Victoria después que la Santiago quedara

\footnotetext{
${ }^{18}$ HERRERA, Antonio de. Historia General de los hechos...Década segunda. Op. cit., p. 303.

19 PIGAFETTA, A. Primer viaje en torno del Globo. Op. cit., pp. 64-65; FERNÁNDEZ DE NAVARRETE, M. Colección de los viajes y descubrimientos que hicieron por mar los españoles desde fines del siglo XV. Madrid: Imprenta Nacional, 1837, pp. 43-44.

20 HERRERA, Antonio de. Historia General de los hechos...Década segunda. Op. cit., p. 303; MARTINIC B, Mateo. Una travesía memorable. Op. cit., p. 139.

${ }^{21}$ PIGAFETTA, A. Primer viaje en torno del Globo. Op. cit., pp. 65-66.
} 
destrozada en Santa Cruz. Si Herrera y Pigafetta obvian poner nombre a los participantes en estas jornadas, José Toribio Medina y Mateo Martinic destacan la intervención de Alonso y dos expedicionarios más, Hernando de Bustamante y Roldán de $\operatorname{Argot}^{22}$.

La llegada de Hernando de Magallanes con las naos Victoria y Trinidad a la bahía del río de las Sardinas se produjo en un momento de relativa calma en la expedición, después de las tensiones vividas en la bahía de San Julián meses atrás y la incertidumbre de encontrar el paso a las Molucas. Estas circunstancias animaron al capitán a disponer de una expedición en chalupa con el objetivo de explorar el camino a recorrer ${ }^{23}$. José Toribio Medina sigue la narración de Pigafetta, quien relata que aprovechando el tiempo que iban a estar en esta zona esperando noticias de la nao San Antonio y aprovisionándose de víveres, Magallanes despachó la citada chalupa bien equipada para que reconociera en tres días el derrotero del canal que podía llevarlos al océano ${ }^{24}$. Y aquí, Medina pone nombres a los integrantes de la chalupa: "Roldán de Argot, lombardero de la Victoria, Bocacio [Ocasio] Alonso, marinero que había sido de la Santiago, y Hernando de Bustamante, barbero de la Concepción" ${ }^{25}$. De acuerdo con Medina, la chalupa enfiló el brazo de mar donde estaban fondeadas las naos Trinidad y Victoria, recorriendo un canal donde alcanzaron un montículo que ascendieron y desde donde pudieron sospechar que el mar se prolongaba detrás de las islas que visualizaban, como así ocurrió varias semanas después. Ese cerro, según Medina, se denominó Campana de Roldán, en honor al artillero Roldán de Argot, y ese nombre lo atestiguan Antonio de Herrera, el cronista Fernández de Oviedo y diversos mapas de la primera mitad del siglo $\mathrm{XVI}^{26}$.

Este descubrimiento para la expedición significó la concesión de sendas cartas de pago por 4.500 maravedíes en nombre de Carlos $\mathrm{V}$ a Ocasio Alonso y Hernando de Bustamante, que las recibieron el 30 de octubre de 1523 estando ya en Castilla, por decisión de Magallanes. La real cédula decretaba abonar esta cantidad por las "albricias cuando saltaron en tierra y se descubrió el Estrecho [de Magallanes]"27. Sin embargo, Roldán de Argot no recibió recompensa en metálico alguna aunque, al igual que Alonso y Bustamante, regresó vivo a Castilla. La redacción de la carta de pago es explícita cuando señala que "saltaron en tierra y se descubrió el Estrecho", y ello solo se pudo distinguir desde el montículo que dio nombre Roldán de Argot, y con cuya noticia, como señala Pigafetta, "todos lloramos de alegría"28.

La armada de Magallanes, después de confirmar la huida de la nao San Antonio a Castilla, enfiló la ruta marcada en el estrecho, que Alonso, Bustamante y Roldán de Argot advirtieron, ahora con rumbo Noroeste en busca de la mar del Sur. Según

\footnotetext{
${ }^{22}$ MARTINIC B. Mateo. Una travesía memorable. Op. cit. p.145; MEDINA, J. T. El descubrimiento del Océano Pacífico. Vasco Núñez de Balboa, Fernando de Magallanes y sus compañeros. Santiago de Chile: Imprenta Universitaria, 1920, pp. CCXL-CCXLIV.

${ }^{23}$ Ibídem, p CCXLI; MARTINIC B. Mateo Una travesía memorable. Op. cit. p. 145.

${ }^{24}$ PIGAFETTA, A. Primer viaje en torno del Globo. Op. cit., pp. 65-66.

${ }^{25}$ MEDINA, José Toribio. El descubrimiento del Océano Pacífico. Op. cit. pp. CCXL-CCXLI.

${ }^{26}$ Ibídem, pp. CCXL-CCXLIV.

27 Información sobre sueldos. AGI, Contaduría, 425 N.1, R.1, f. 57v.

${ }^{28}$ PIGAFETTA, A. Primer viaje en torno del Globo. Op. cit., p. 66.
} 
Herrera, "al cabo de veinte días que navegó por aquella estrechura, a veinte y siete de noviembre, salió al espacioso mar del Sur, dando infinita gracias a Dios que le había dejado hallar lo que tanto deseaba..."29. Desde que salieron de Sanlúcar de Barrameda hasta encontrar el que después se conoció como Mar Pacífico, habían fallecido dieciséis miembros de la tripulación ${ }^{30}$.

\section{Ocasio Alonso: testigo en la probanza de posesión del Maluco}

El siguiente espacio donde Ocasio Alonso jugó un papel protagónico fue en las Molucas, el propósito final del viaje. Gracias a la Probanza sobre la posesión del Maluco que se le realizó en Badajoz, como testigo superviviente, Alonso expuso en las respuestas al cuestionario que se le planteó los pasos que siguió la expedición por las "islas de las Especias" "31. Empero, antes de alcanzar el objetivo políticocomercial, la expedición hubo de atravesar el denominado "Mar del Sur", "que parecía cada día más espacioso", como resalta Herrera, poniendo rumbo Oeste Noroeste desde que salieron del Estrecho de Todos los Santos ${ }^{32}$. Y las condiciones y situaciones que debió soportar Alonso hasta llegar a las Molucas no sólo fueron embarazosas sino que llegaron a ser críticas para él, miembro de la nao Victoria, y el resto de la expedición.

En este inmenso océano recorrieron dos mil leguas sin divisar más que dos islas donde se proveyeron de mantenimiento. De allí, "navegaron después ochocientas leguas, hasta que a los veinte de enero... hallaron dos islas muy hermosas, y de mucha gente bestial..." "Nombraron a estas islas "Velas Latinas", aunque también se le conocieron como "Islas de los Ladrones", debido a los múltiples hurtos y robos que padecieron en el contacto con los naturales. De allí navegaron trescientas leguas rumbo al Oeste, donde encontraron muchas islas, llegando la expedición a la isla de Zebú, en el archipiélago que los castellanos, años más tarde, llamaron Filipinas. Después de hacer las paces con el rey de la isla, la expedición recibió provisiones a cambio de "cascabeles, cristalinas y otras cuentas de vidrio" para seguir avanzando en su camino a las Molucas. Los acontecimientos se fueron sucediendo cuando en la isla de Mactán, vecina de Zebú, en un intento de Hernando de Magallanes por pretender que su rey reconociese al emperador Carlos, aquél fue muerto en batalla el 20 de abril de 1521. Junto a él, sucumbieron el capitán de la nao Victoria y seis hombres más ${ }^{34}$. Días más tarde, el rey de Zebú, aparentemente aliado de los expedicionarios, invitó a una comida a Duarte Barbosa, sustituto de Magallanes como capitán general, al nuevo capitán de la Victoria, Luis Alfonso, y al de la Concepción, Juan Rodríguez Serrano. Esta comida se convirtió en una trampa mortal, donde éstos murieron junto a otros 25 miembros de la armada castellana. Este desastre ocasionó que hubiese que cambiar de nuevo a los dirigentes de la expedición - Juan Carballo, como capitán general, y Gonzalo Gómez de Espinosa, capitán de la nao Victoria - y quemar la Concepción, al no haber tripulantes

\footnotetext{
${ }^{29}$ HERRERA, Antonio de. Historia General de los hechos...Década segunda. Op. cit., p. 303.

${ }^{30}$ FERNÁNDEZ DE NAVARRETE, Martín. Colección de los viajes... Op. cit., p. 50.

${ }^{31}$ Probanza sobre la posesión del Maluco en Badajoz, 1524, AGI, Patronato, 48, R. 15.

32 HERRERA, A. de. Historia General de los hechos de los castellanos en las islas y tierra firme del Mar Oceáno. Década Tercera. Madrid: Imprenta Real, 1601, p. 5.

${ }^{33}$ Ibídem.

${ }^{34}$ Ibídem, pp. 6-8.
} 
suficientes para tres naos. Más adelante, en Burney (Borneo), se destituyó a Carballo y Gómez de Espinosa se convirtió en capitán general de la armada, mientras que Juan Sebastián Elcano pasó a capitán de la Victoria. Antes de partir al Maluco, las naves estuvieron detenidas cerca de cuarenta días reparando y adobando desperfectos ${ }^{35}$.

El camino a las denominadas "Islas de las Especias" se hizo más franqueable, a pesar de contar con dos naves y varias decenas de bajas, entre ellas la más sensible la del capitán general Hernando de Magallanes. De acuerdo con Leonard Andaya, en el momento de la llegada de la expedición castellana a las Molucas había cuatro reinos importantes, Ternate, Tidore, Gilolo y Bachan, bajo el control de gobernadores convertidos al islam. Tidore fue la isla elegida para el desembarco. El motivo de llegar aquí, más que fuera el lugar donde afirmaban que podrían encontrar más clavo, pudo deberse a que el gobernante de Ternate era partidario de la presencia portuguesa en la zona ${ }^{36}$.

Es ahora cuando damos la palabra a Ocasio Alonso y acudimos a su declaración en la Probanza sobre la posesión del Maluco para conocer con detalle el paso de la expedición por las islas Molucas. Alonso resume su experiencia recalcando "la dificultad del viaje, por impedimentos y tiempos contrarios y dificultad de los lugares por donde pasamos, nos detuvimos en el camino y tardamos en llegar..."37. Dos años y tres meses desde que salieron de Sanlúcar de Barrameda, el 8 de noviembre de 1521 las naos Victoria y Trinidad enfilaron su entrada en la isla de Tidori, y "surgieron junto a la villa, por ser la mar muy honda, hicieron salva, envió el rey a saber quiénes eran, y recibió gran placer de su llegada" "38. Allí les acogió el sultán de Tidori, Al-Mansur, con todo su pueblo apostado en el pequeño embarcadero de la isla, "e llegados los dichos capitanes le besaron las manos y le dijeron cómo iban por mandado de Su Majestad el rey de Castilla a tomar posesión de la dicha isla que le pertenecía..."

Alonso sigue relatando, porque lo vio, estuvo presente y así lo recalca, cómo AlMansur prestó obediencia al rey de Castilla, y en su nombre, a los capitanes de la Armada, aceptando a Carlos I como rey y señor de su isla y reino y que "se reconocía y reconoció por sujeto de Su Majestad e obediencia en todo lo que le enviase...", recibiendo los capitanes de la expedición, en nombre del rey, la dicha isla y sus dominios ${ }^{40}$. Esta obediencia implicaba que Al-Mansur dejaba de ser sultán 0 rey de Tidori y se convertía en gobernador del rey de España en su antiguo señorío. Para ratificar esta subordinación solicitó a los capitanes "que le dejasen una bandera de las armas de la Corona Real de Castilla y ciertos tiros de artillería para que se quedasen en la dicha isla en reconocimiento de la isla y para la guarda y defensa"41. Ocasio Alonso hace referencia al gesto diplomático de Al-Mansur para afirmar su

\footnotetext{
${ }^{35}$ Ibídem, pp. 17-20.

${ }^{36}$ ANDAYA, L. Y. Los primeros contactos de los españoles con el mundo, de las Molucas en las Islas de las Especias. Revista Española del Pacífico. 1992, n. 2, año II, pp. 63-69.

${ }^{37}$ Probanza sobre la posesión del Maluco en Badajoz, 1524, AGI, Patronato, 48, R. 15, f. $24 \mathrm{v}$.

${ }^{38}$ HERRERA, Antonio de. Historia General de los hechos... Década Tercera. Op. cit., p. 21.

${ }^{39}$ Probanza sobre la posesión del Maluco en Badajoz, 1524, AGI, Patronato, 48, R. 15, f. 24v.

${ }^{40}$ lbídem.

${ }^{41}$ Ibídem, ff. 24v-25r.
} 
amistad y reconocimiento al monarca español, enviándole "ciertos presentes de los frutos y cosas de las islas, que fueron especias y penachos y cofres" ${ }^{\prime 2}$, una de las tradiciones más típicas de las comunidades indígenas del Pacífico: la entrega de ofrendas y presentes en agradecimiento de amistad. Sin embargo, los castellanos no se quedaron atrás en el reparto de presentes. Obsequiaron al sultán de Tidori con "un sillón de terciopelo rojo, y se le regaló un ropaje de terciopelo amarillo confeccionado a la moda turca", al igual que a miembros de su Corte con otros objetos de lujo ${ }^{43}$. Según Andaya, este trato hacia el sultán y los miembros de su Corte indica que los españoles conocían bien la costumbre de la región. La presencia de portugueses en la expedición, que pudieron haber visitado regiones cercanas con anterioridad, como era el caso de Hernando de Magallanes, puede explicar el conocimiento de los gustos de estas dirigencias ${ }^{44}$. $Y$ todo este contexto de cesión de poderes, de reconocimientos y de reparto mutuo de presentes fue seguido de celebraciones, "en señal de placer y contentamiento que tenían por lo haber hecho tocaban muchos instrumentos de música y muchas fiestas de placer y alegría y de mucho goce" ${ }^{\prime 4}$. También cuenta Alonso el gusto del sultán de Tidori por la astrología, y gracias a ella "e del asiento de la luna había sabido que un rey grande e poderoso a quien pertenecía las dichas islas enviaba a las tomar..."46.

Ocasio Alonso, en la declaración de la probanza también dejó testimonio de la llegada a la isla de Tidore de los reyes y principales del resto de islas del Maluco, de Ternate, Moti, Makian, Bachan y Gilolo, que fueron a reconocer la autoridad del rey de Castilla sobre la región y mostrar sus obediencias, "según y de la manera que lo había hecho el dicho rey de Tidori" con anterioridad. Al igual que Al-Mansur, estos dirigentes querían permanecer como gobernadores de sus territorios en nombre del monarca hispano y regresaron a ellos con "las banderas de Castilla desplegadas delante de los navíos e otras suyas atrás lo cual pareció que era señal de su sujeción e por honra del rey de Castilla" ${ }^{, 3}$. Sin embargo, detrás de esta plácida convivencia entre estos reinos, la rivalidad era manifiesta como advirtieron los portugueses en 1511 cuando se instalaron en Malaca. De acuerdo con Andaya, las hostilidades eran evidentes, en especial, entre los reinos de Tidore y Ternate, desde que los lusos se aliaron con este último para tener una relación comercial preferente. Es por ello que cuando llegaron las naos castellanas a Tidore, Al Mansur vio en sus tripulantes a sus benefactores y ofreció su cargo y reino al monarca español y a su protección ${ }^{48}$. Detrás de estas buenas relaciones, la intención del gobernador de Tidore era consolidar su amistad con el reino de Castilla para mantener fuera de sus fronteras territoriales a la gente de Ternate que, a su vez, sostenían alianzas con los

\footnotetext{
${ }^{42}$ Ibídem, f. 25r.

${ }^{43}$ ANDAYA, Leonard Y. Los primeros contactos de los españoles. Op. cit., p. 70.

${ }^{44}$ Ibídem. Sobre la presencia portuguesa en la "Especiería" con anterioridad a la expedición de Hernando de Magallanes de 1520, véase: MORENO MADRID, J. M. En torno a la expedición de Antonio de Abreu y Francico Serrão (1511-1521). En: Filipinas y el Pacífico: de los viajes por mar a los viajes por la red. Hacia la construcción de una herramienta de aprendizaje en línea [en línea]. Madrid: Proyecto Innova-Docentia-Convocatoria 2016-2017. No. de referencia: 219, Universidad Complutense de Madrid. Disponible en <https://www.ucm.es/data/cont/docs/1035-2017-06-122.\%20EXPEDICI\%C3\%93N\%20ABREU-SERRAO.pdf>.

${ }^{45}$ Probanza sobre la posesión del Maluco en Badajoz, 1524, AGI, Patronato, 48, R. 15.

${ }^{46}$ Ibídem, f. 24v.

47 Ibídem, f. 25v.

${ }^{48}$ ANDAYA, Leonard Y. Los primeros contactos de los españoles. Op. cit., pp. 71-72.
} 
portugueses, rivales de los castellanos por el control de los mares.

La estancia de los expedicionarios en las islas de la Especiería, de todas maneras, estuvo amenazada y condicionada por la presencia portuguesa en la zona. La Corona de Portugal no terminó de aceptar que sus competidores en los mares hubieran descubierto otro camino que llevase a dichas islas, que se conoció como "ruta española del Pacífico", a la que después se sumó la ruta del "Galeón de Manila - Nao de la China" con salida y llegada en el puerto novohispano de Acapulco ${ }^{49}$. Ocasio Alonso, testificó que los reyes y señores de estas islas no reconocían por señor al rey de Portugal, "porque la dicha provincia era libre y no reconocían otro señor ni superior alguno a los dichos sus reyes" ${ }^{50}$.

La "Probanza sobre la posesión del Maluco" no da pista alguna sobre los intereses comerciales de la expedición castellana, ni sus testigos, incluido Ocasio Alonso, hacen referencia a la adquisición y comercio de especias. Sin embargo, a pesar de esta evidente omisión al tratarse de un documento oficial que había que confrontar con la diplomacia portuguesa en las Juntas de Badajoz-Elvas de 1524, la obtención de especias, en especial el clavo, se convirtió en el objetivo cardinal desde los primeros días de estancia de los castellanos en Tidore. Hay que acudir a Antonio Pigafetta integrante de la expedición y cronista del "Primer viaje en torno del Globo", para conocer el intercambio que hicieron los españoles en Tidore de las mercancías europeas que llevaban (paños, telas, cobre, hachas, tazas de vidrio, cinabrio y azogue) para conseguir cantidades importantes de clavo, el principal producto por el que se interesaron. Además, Pigafetta tuvo tiempo para recorrer los campos donde los tidorenses cultivaban los árboles de clavo y ver cómo se producía la nuez moscada y el jengibre ${ }^{51}$. Así, los barriles de especias se fueron amontonando, llenando las bodegas, cubiertas y puentes de la Trinidad y la Victoria, siendo esta última la que soportó mayor cantidad de carga por encontrarse en mejores condiciones técnicas.

Días antes de la Navidad de 1521 las naos Victoria y Trinidad estaban prestas para volver a la península lbérica. Finalmente, debido a un problema de vía de agua que afectó a la Trinidad, sólo pudo partir la Victoria, dejando en Tidore a cincuenta y tres miembros de su tripulación ${ }^{52}$. Pigafetta señala que la Victoria partía con

\footnotetext{
49 Sobre la presencia portuguesa en la denominada "Especiería" y en concreto en el archipiélago de las Molucas, así como el desarrollo de los conflictos sobre este territorio entre las Coronas castellana y portuguesas, véanse: HIDALGO NIETO, M. La cuestión hispano-portuguesa en torno a las islas Molucas. Revista de Indias. 1942, vol. III, n. 9, pp. 429-462; SÁNCHEZ MARTíNEZ, A. De la 'cartografía oficial' a la 'cartografía jurídica': la querella de las Molucas reconsiderada, 1479-1529. Nuevo Mundo Mundos Nuevos [en línea]. 2009. Disponible en $<$ http://nuevomundo.revues.org/index56899.html>.

${ }^{50}$ Probanza sobre la posesión del Maluco en Badajoz, 1524, AGI, Patronato, 48, R. 15, f. 25 v.

${ }^{51}$ PIGAFETTA, A. Primer viaje en torno del Globo. Op. cit., pp. 148, 155-156.

52 La Trinidad, al mando del capitán Gonzalo Gómez de Espinosa, permaneció varios meses en Tidore mientras se arreglaba su casco, "el cual acordaron que con la nao Trinidad, en estando aderezada, tomase la vuelta de Panamá, a Castilla del Oro, para que descargando allí, y pasando la carga al mar del Norte (como muchas veces había platicado que había que hacer) pudiese la especiería ir a Castilla”, HERRERA, Antonio de. Historia General de los hechos... Década Tercera. Op. cit., p. 23. Sin embargo, iniciado el viaje de vuelta, después de muchas vicisitudes y viendo las dificultades que se le presentaban, decidió volver a las islas del Maluco con el inconveniente que la
} 
"cuarenta y siete europeos y trece indios", con Ocasio Alonso a bordo ${ }^{53}$. Sus bodegas iban repletas de especias y tomaron "la vía que de la India hacían los portugueses" $"$.

\section{El viaje de vuelta a Castilla: Ocasio Alonso, cautivo en Cabo Verde}

El viaje de regreso de la nao Victoria a Castilla fue una auténtica aventura, protagonizada por la precaución de no ser sorprendidos por los portugueses. La Probanza sobre la posesión del Maluco no ofrece información de este periplo. Empero, Antonio de Herrera y Antonio Pigafetta siguen siendo las referencias más fidedignas para relatar la última etapa de la travesía que llevó a la expedición de vuelta a Sevilla. Desde Tidore hasta llegar a Castilla el viaje se centró en evitar a los portugueses, que controlaban dicha ruta por ser su área de influencia de acuerdo al Tratado de Tordesillas.

La Victoria, antes de doblar el cabo de Buena Esperanza, tuvo que cruzar el archipiélago de las Molucas, transitar por Timor y evitar ir hacia el Norte para "no ser vistos de portugueses", como indica Herrera, o "por miedo a los portugueses", como dejó escrito Pigafetta en su diario ${ }^{55}$. A pesar de ello, en este trayecto, previo a adentrarse de lleno en el Índico con rumbo Oeste-Suroeste, pudieron abastecerse de otras especias como pimienta, jengibre y canela, además de vituallas para pasar el camino. A principios de mayo de 1522, la nao Victoria cruzó el Cabo de Buena Esperanza, después muchas dificultades climáticas y técnicas por los vientos en contra y siguiendo rumbo Norte enfilaron la costa africana ${ }^{56}$. Sin apenas agua ni víveres, sumidos en la inanición y el hambre, llegaron a la altura' de la colonia portuguesa de Cabo Verde. Pigafetta señala que este escenario provocó la muerte de más de veinte tripulantes, entre europeos y naturales de las Molucas que venían a bordo ${ }^{57}$.

El 1 de julio, "con extrema necesidad, sin haber comido en mucho tiempo sino arroz", la expedición se encontraba a escasas leguas de las islas de Cabo Verde ${ }^{58}$. La tripulación deliberó y se decidió ir a las islas por víveres, prevenidos porque estaban en tierras portuguesas y venían de lugares que podían estar en disputa diplomática. Sin embargo, fue hasta el 9 de julio cuando un esquife o bote con una decena tripulantes, donde se encontraba Ocasio Alonso, logró llegar a la isla Santiago de Cabo Verde a aprovisionarse "y nos recibieron muy bien, y nos dieron mantenimiento cuantos quisimos" $" 59$. El buen trato recibido por los portugueses impulsó a repetir la operación al día siguiente. Pigafetta, testigo presencial de estas

\footnotetext{
nao fue apresada por los portugueses y llevada su tripulación a Lisboa hasta su liberación posterior; véanse, HERRERA, Antonio de. Historia General de los hechos... Década Tercera, Op. cit., pp. 140143, y PÉREZ-MALLAÍNA, Pablo Emilio. Tierras por descubrir y ganar. En: LUCENA SALMORAL, Manuel (coord.). Historia de Iberoamérica. Tomo II, Historia Moderna. Madrid: Cátedra, 2002, p. 98.

${ }^{53}$ PIGAFETTA, A. Primer viaje en torno del Globo. Op. cit., p. 168.

${ }^{54}$ HERRERA, Antonio de, Historia General de los hechos... Década Tercera, Op. cit., p. 139.

${ }^{55}$ Ibídem, p. 139; PIGAFETTA, A. Primer viaje en torno del Globo. Op. cit., p. 183.

56 Ibídem, pp. 183-184.

57 Ibídem, p. 184.

${ }^{58}$ HERRERA, Antonio de. Historia General de los hechos... Década Tercera, Op. cit., p. 139.

${ }^{59}$ FERNÁNDEZ DE NAVARRETE, Martín. Colección de los viajes... Op. cit., p. 92.
} 
acciones, señala que tuvieron que mentir, que venían de las costas de América y no de la Especiería, pues eran conscientes que estaban en territorio hostil ${ }^{60}$. De nuevo, Alonso y once miembros más de la Victoria volvieron a la isla el 14 julio por más bastimentos para atender a los más enfermos, por ayuda para solucionar problemas técnicos de la nao y en esta ocasión iban a pagar con tres quintales de clavo, al no tener dinero. Sin embargo, el batel no regresó a la Victoria. Se esperó un día su retorno y la respuesta de los portugueses fue una proposición de rendición para ser enviados a la península lbérica en una nao de su nación que venía de las Indias. La réplica del capitán Juan Sebastián Elcano fue levantar velas y poner rumbo a Castilla, con veintidós tripulantes, dejando en la isla de Santiago a los doce expedicionarios, entre ellos Ocasio Alonso, que fueron apresados por los portugueses $^{61}$.

El 6 de septiembre de 1522 la nao Victoria llegó a Sanlúcar de Barrameda, prácticamente con los elementos técnicos precisos para poder remontar el Guadalquivir y atracar en Sevilla. Dos días más tarde el barco arribó en el muelle hispalense de Las Muelas listo para pasar los registros administrativos de la Casa de Contratación. Empero, pese al alcance del viaje - se había efectuado la primera circunnavegación de la tierra -, las peticiones que el capitán de la Victoria, Juan Sebastián Elcano, exigió en una misiva a Carlos $\mathrm{V}$, quien se encontraba en Valladolid, fueron la libertad de sus marinos prisioneros en Cabo Verde, que hiciera todo lo posible por premiar a sus compañeros y que se les librara a todos los supervivientes de los impuestos de las especias que para sí traían en la Victoria ${ }^{62}$. El rey no tardó en responder al marino vasco. El 13 de septiembre le escribió que ya había mandado resolver el asunto de la liberación de los presos en tierras portuguesas, señalando además que "les concedía a él y sus compañeros, acatando sus servicios y trabajos, la cuarta parte de la veintena que le pertenecía en las cajas y quintaladas que le había pedido" "63.

Una vez que la nao Victoria llegó a Sevilla, con la noticia que había circunnavegado el orbe, llegado a La Especiería, la bodega y cubierta del barco repletas de barriles de especias, pero con parte de la tripulación cautiva en tierras portuguesas de África, afloró el problema entre las dos Coronas ibéricas. El rey de Portugal Juan III protestó ante el emperador Carlos V por la intromisión de la expedición castellana en territorio que correspondía a los lusos, además del robo de especias; por su parte, el monarca hispano centró su reclamación en la puesta en libertad de los doce miembros de la tripulación de la Victoria retenidos en Cabo Verde $^{64}$.

Mientras tanto, Ocasio Alonso y sus once compañeros estuvieron presos en la isla de Santiago hasta que llegó una nave portuguesa procedente de la India con destino a Lisboa en la que fueron embarcados. De acuerdo con José Toribio Medina,

\footnotetext{
${ }^{60}$ PIGAFETTA, A. Primer viaje en torno del Globo. Op. cit., pp. 184-185.

${ }^{61}$ FERNÁNDEZ DE NAVARRETE, Martín. Colección de los viajes... Op. cit., pp. 92-94; HERRERA, Antonio de, Historia General de los hechos... Década Tercera, Op. cit., p. 139.

${ }^{62}$ COMELLAS, J. L. La primera vuelta al mundo. Madrid: Ediciones Rialp, 2012, p. 39.

${ }^{63}$ MEDINA, José Toribio. El descubrimiento del Océano Pacífico. Op. cit, p. CCCXXV.

${ }^{64}$ SÁNCHEZ MARTÍNEZ, Antonio. De la 'cartografía oficial'. Op. cit., p. 14.
} 
a fines de septiembre de 1522 los cautivos se encontraban en la capital portuguesa, pues el 28 de ese mes Juan III envió una misiva a su embajador en la corte castellana para que reclamara ante el monarca hispano la llegada de la nao Victoria a los dominios portugueses de Cabo Verde "con un cargamento de clavo sacado de territorio perteneciente a Portugal", pidiendo castigo para el capitán de la nao y la devolución de la mercancía. Los presos también pudieron escribir desde Lisboa, el 10 de octubre de 1522, a los oficiales de la Casa de la Contratación en Sevilla, dándoles avisos de su situación ${ }^{65}$. La presión de Carlos V, además de las promesas de iniciar conversaciones para tratar el asunto de las Molucas y su lugar en los mapas después del Tratado de Tordesillas de 1494, surtió efecto y los marineros retenidos en Lisboa fueron liberados cinco meses y medio después de llegar la nao Victoria procedente de las Molucas. El 25 de febrero de 1523 Ocasio Alonso llegó a Sevilla, de acuerdo a los datos proporcionados por la Casa de la Contratación, y allí siguió residiendo buena parte del año a la espera de recibir sus salarios y recompensas ${ }^{66}$.

\section{Ocasio Alonso, testigo entre cosmógrafos y cartógrafos}

El conflicto político por el control de las Molucas, generado entre las dos monarquías ibéricas, se buscó reconducirlo a través de la vía diplomática. Entre el 11 de abril y el 31 mayo de 1524 se celebraron las Juntas de Badajoz-Elvás, en la frontera hispano-lusa, con el propósito de intentar solucionar las discrepancias provocadas por la llegada de las naos castellanas a las Molucas. Se pretendió determinar la posición de la línea de demarcación del Tratado de Tordesillas para fijar la llamada "contralínea" que fijase la longitud donde quedaban la Molucas, si en el lado portugués o en el castellano. El debate que se originó en las Juntas de 1524 tuvo a las islas de Cabo Verde como eje central del mismo, pues no se pudo acordar desde qué punto del archipiélago se debía iniciar la cuenta de las 370 leguas hacia el Oeste, y ese detalle determinaba la posesión de las Molucas. Estas negociaciones, en palabras de Sánchez Martínez, resultaron un fracaso estrepitoso ${ }^{67}$.

Sin embargo, protagonistas de estos debates en Badajoz y Elvás fueron dieciséis de los supervivientes que regresaron de las Molucas en la nao Victoria y de los retenidos en Cabo Verde. Y entre estos declarantes se hallaba Ocasio Alonso, que en 1523, después de su liberación por los portugueses, estaba asentado en Sevilla. Las deposiciones del marinero bollullero y de sus compañeros de viaje se consideraron significativas, más bien por los datos etnográficos, geográficos y cosmonáuticos, como complemento de las pruebas presentadas por la parte española ${ }^{68}$. En su declaración, Ocasio Alonso fue preguntado si sabía que todas las tierras que estaban al Oeste de la línea que se asentó y capituló en Tordesillas en 1494 pertenecían al rey de Castilla y que por este Tratado las tierras e islas de

\footnotetext{
${ }^{65}$ MEDINA, José Toribio. El descubrimiento del Océano Pacífico. Op. cit., p. CCCXXVII.

${ }^{66}$ Ibídem, p. CCCXLV; MEDINA, J. T. Colección de Documentos Inéditos para la Historia de Chile. Tomo I. Santiago de Chile: Imprenta Ercilla, 1888, p. 178; Información sobre sueldos, mercancías y mercedes relativas a la Armada a la Especiería organizada por Fernando de Magallanes, 1524-1534, AGI, Contaduría, 425 N.1, R.1, f. 10v.

${ }^{67}$ SÁNCHEZ MARTÍNEZ, Antonio. De la 'cartografía oficial'. Op. cit., p. 15.

${ }^{68}$ Probanza sobre la posesión del Maluco en Badajoz, 1524, AGI, Patronato, 48, R. 15.
} 
Maluco le correspondían. Además de hacer referencias a la organización de la expedición y las dificultades que pasaron hasta llegar a la isla de Tidore, dos años después de su salida de Sevilla, las cuestiones centrales se encaminaron a hacer valer la incorporación de las islas de Maluco y la obediencia de los reyes de sus diferentes islas al reino de Castilla. Por último, las preguntas finales buscaban saber que las islas no estaban dominadas por el rey de Portugal ni otra nación y, de acuerdo a los instrumentos de marinería que utilizaban, las islas de Maluco entraban dentro de los límites que determinaba el Tratado de Tordesillas, que situaba la línea de demarcación a partir de las 370 leguas al oeste del archipiélago africano de Cabo Verde $^{69}$.

La Junta de Badajoz de 1524 no resolvió, ni dilucidó, el asunto de la pertenencia de las islas de la Especiería. Muchos científicos, castellanos y portugueses, adujeron que con los instrumentos de aquel momento no era posible precisar la longitud de dichas islas, aunque las situaban en la zona española. Pero también, como señala Miguel Pino, "no debe perderse de vista el importante dato de que fueron los portugueses los primeros que habían llegado a la zona"70. Es por ello que este asunto diplomático, y que afectaba a dos potencias vecinas, tuviese que esperar al 2 de abril de 1529 cuando en el llamado Tratado de Zaragoza, Castilla hacía cesión a Portugal de las islas Molucas por un valor de 350.000 ducados de oro, mientras que el emperador Carlos $\mathrm{V}$ se guardaba para sí la futura ocupación de Filipinas que habían conocido antes que los portugueses en el viaje de Magallanes ${ }^{71}$. A partir de ahora, las expediciones a la Mar del Sur no se harían desde la Península Ibérica sino desde Nueva España o Perú, y la dificultad sería encontrar el viaje de vuelta ${ }^{72}$.

\section{Ocasio Alonso, cobros de sueldos, familia y herencia}

Ocasio Alonso, como ya se hizo referencia, estaba asentado desde febrero de 1523 en Sevilla una vez que fue liberado por los portugueses, cerca de su natal Bollullos, en los contornos del condado de Niebla. La intención del marinero era reembolsarse los salarios, deudas y recompensas correspondientes a los más de tres años pasados en la expedición de Hernando de Magallanes y las cárceles portuguesas. Recordemos que Alonso se alistó como marinero en la nao Santiago, capitaneada por Juan Rodríguez Serrano. De acuerdo con el sueldo estipulado, aquellos que oficiaban de marineros debían recibir mensualmente 1.200 maravedíes

\footnotetext{
${ }^{69}$ Ibídem, ff. 1r-3v.

70 PINO ABAD, M. El Tratado de Zaragoza de 22 de abril de 1529 como anticipo a la conquista de Filipinas. En: FERNÁNDEZ RODRÍGUEZ, M. (coord.). Guerra, derecho y política. Aproximaciones a una interacción inevitable. Valladolid: Asociación Veritas para el Estudio de la Historia, el Derecho y las Instituciones, 2014, pp. 28-29. Véase además, HIDALGO NIETO, Manuel. La cuestión hispanoportuguesa... Op. cit., pp. 429-462 y SÁNCHEZ GONZÁLEZ, D. M. Aspectos jurídicos de la negociación de las Molucas. Boletín de la Facultad de Derecho. 1993, n. 3, pp. 293-310.

${ }^{71}$ Antonio García Abásolo recalca que el Tratado de Zaragoza de 1529 marcó dos etapas en el interés de la Corona hispana por el Pacífico. Antes de la firma de este Tratado el objetivo final eran las Molucas; después del mismo "el objetivo fue encontrar un asentamiento propicio, que terminó siendo Filipinas"; GARCÍA ABÁSOLO, A. La primera exploración del Pacífico y el asentamiento español en Filipinas. En: ELIZALDE PÉREZ GRUESO, M. D. Las relaciones entre España y Filipinas. Siglos XVI-XX. Madrid: CSIC, 2002, pp. 21-22.

72 PINO ABAD, Miguel. El Tratado de Zaragoza... Op. cit., pp. 29-33.
} 
mensuales ${ }^{73}$. Además, era costumbre que los miembros de la tripulación recibieran sueldos adelantados, "de socorro", y Ocasio Alonso percibió en Sevilla, antes de levantar velas, 4.800 maravedíes correspondientes a cuatro meses ${ }^{74}$.

El sueldo que correspondió al marinero Ocasio Alonso, desde que la Armada de Hernando de Magallanes partió de Sevilla el 10 de agosto de 1519 hasta su regreso al puerto de Las Muelas hispalense el 8 de septiembre de 1522, se dividió en dos etapas y varios conceptos. Antes de partir, como se refirió, recibió de adelanto 4.800 maravedíes que habría que restar a la cantidad final. Su primera etapa como marinero estuvo a bordo de la nao Santiago, hasta el 22 de mayo de 1520 "que son nueve meses y doce días", por la que recibió 11.280 maravedíes $^{75}$. Después que la Santiago quedó destrozada e inservible en el río de Santa Cruz y sus 37 hombres se repartieron en las tres naos restantes, Alonso continuó como marinero en la Victoria el tiempo que duró la expedición hasta que fue retenido en la isla de Santiago de Cabo Verde por los portugueses ${ }^{76}$. A pesar de este inconveniente se le saldó, al igual que a todos los retenidos en tierras lusitanas, como si hubiera completado la expedición en Sevilla el 10 de septiembre de 1522. Por esta partida recibió la suma total a 39.520 maravedíes, ya descontados los 4.800 de adelanto o de "socorro". Además, se le extendió una suma de 6.540 maravedíes por los cinco meses y catorce días que permaneció preso de los portugueses en la isla de Santiago, en Cabo Verde, y Lisboa. Así, el 19 de junio de 1523 se le dio a Ocasio Alonso una carta de pago de 46.060 maravedíes. A diferencia de la mayoría de los expedicionarios que alcanzaron el puerto de Sevilla, que traían consigo diferentes quintales y libras de clavo y especias, el hecho de que Alonso quedara preso en Cabo Verde y no llegara a puerto en la nao Victoria le impidió recibir la quintalada ${ }^{77}$.

El 30 de octubre de 1523 Ocasio Alonso recibió otra carta de pago, esta vez por 4.500 maravedíes. Una real cédula decretaba satisfacer esta cantidad a Alonso y a Hernando de Bustamante, barbero de la nao Concepción, por decisión de Hernando de Magallanes por las "albricias cuando saltaron en tierra y se descubrió el Estrecho [de Magallanes]" ${ }^{78}$.

Asimismo, desde 1523 hasta 1532 Ocasio Alonso recibió hasta seis pagos de diferentes deudas que se originaron durante el viaje con varios compañeros de la expedición. Ningunos de sus deudores llegó a Sevilla en septiembre de 1522, ni estuvieron con él retenidos en Cabo Verde y Lisboa. Uno, Martín de Ayamonte, huyó nadando, después de partir del Maluco, a la isla de Timor $^{79}$. Los otros cinco

\footnotetext{
${ }^{73}$ MEDINA, José Toribio. El descubrimiento del Océano Pacífico..., Documentos. Op. cit. pp. 199 y 205.

${ }^{74}$ Relación de expedicionarios que fueron en el viaje a la Especiería, sus procedencias, cargos y sueldos, agosto de 1519. AGI, Contratación, 5090, L.4, f. 51r.

75 Información sobre sueldos. AGI, Contaduría, 425 N.1, R.1, f. 10v.

${ }_{77}^{76}$ MEDINA, José Toribio. El descubrimiento del Océano Pacífico..., Documentos. Op. cit., p. 211.

77 Información sobre sueldos. AGI, Contaduría, 425 N.1, R.1, f. 10v. La quintalada era la cantidad resultante de un tanto por ciento del producto de un flete, aproximadamente un dos y medio, una vez sacado el daño de avería, que se repartía entre los miembros de la tripulación que más había trabajado en el viaje.

${ }^{78}$ Ibídem, f. 57v.

${ }^{79}$ MEDINA, José Toribio. Colección de Documentos Inéditos. Op. cit., p. 179.
} 
fallecieron entre junio y julio de 1522, después que la nao Victoria pasó el cabo de Buena Esperanza y se encontraba cercana a las islas de Cabo Verde ${ }^{80}$. De estos, Martín de Magallanes, Bernardo Mauri y el grumete Domingo traían consigo importantes cantidades de especias. De las ventas procedentes del clavo, recayeron en Alonso 13.159 maravedíes, más la parte que le debía corresponder de lo que se pagaron al grumete de la Victoria, fallecido en mayo de 1522, Bernardo Mauri, "a Nuestra Señora de la Victoria y a Ocasio Alonso y a Miguel de Rodas y Juan Blanco, por su hijo Andrés Blanco, y a Juan de Arratia y a Pedro de Tolosa, como parece en el libro de los sueldos por 28.769". Además, recibió 10.375 maravedíes de las deudas que contrajeron con él Martín de Ayamonte, Cristóbal de Acosta y Pierre Gascón ${ }^{81}$.

La última referencia directa que hay sobre Ocasio Alonso se sitúa en 1532, precisamente cuando recibió el pago de la deuda que con él tenía Pierre Gascón. A partir de aquí sólo hay datos conocidos de sus herederos, todos ligados con las Indias. Así, su hijo Antón de Espina partió para la isla de La Española en septiembre de $1538^{82}$. Allí se casó con Beatriz de Salinas, vecina de la isla, y en 1567 tuvieron como hijo a Gerónimo de Espina ${ }^{83}$. Antón falleció en Santo Domingo antes de 1578. Esta circunstancia debió obligar a Gerónimo, con once años de edad, ir a Castilla, a la tierra donde nacieron su abuelo y su padre. El 6 de mayo de 1578 obtuvo licencia otorgada por el gobernador de Santo Domingo, Gregorio Gómez de Cuenca, para que en el primer navío que saliese para Castilla "pueda ir por cuanto va de consentimiento de la dicha su madre a cobrar cierta herencia que dejó el dicho su padre en la villa de Bollullos" ${ }^{\prime 4}$. El patrimonio que percibió puede presumirse que en su mayor parte provenía de las rentas que Ocasio Alonso, su abuelo, logró reunir y dejó a su hijo Antón de Espina. La estancia de Gerónimo de Espina en Bollullos fue breve, aproximadamente un año. Una vez cumplido su objetivo, solicitó cédula para poder volver a la isla de La Española ${ }^{85}$.

\section{Conclusión}

Hernando de Magallanes y Juan Sebastián Elcano han quedado enmarcados en la mayoría de los libros de Historia como los grandes protagonistas de una hazaña hasta entonces jamás realizada. Sin embargo, la vuelta al orbe no fue el objetivo de la expedición que el marinero portugués inició y el vasco culminó. El desconocimiento de un océano como el Pacífico, que se navegaba por los castellanos por primera vez en dirección Oeste, con unos vientos a favor y "sin la certeza de hallar un viento favorable para el regreso", como señala Felipe Fernández

\footnotetext{
80 Pigafetta señala que durante esos meses, "y en este intervalo, perdimos veintiún hombres, cristianos e indios", carecían de víveres y si no hubiesen llegado a las islas de Cabo Verde hubiesen muertos todos; PIGAFETTA, A. Primer viaje en torno del Globo. Op. cit., p. 184.

${ }^{81}$ MEDINA, José Toribio. Colección de Documentos Inéditos. Op. cit., pp. 179-183.

82 Libro de asiento de pasajeros, AGI, Contratación, 5536, L.5, f. 123r.

83 Licencia a Gerónimo de Espina, de edad de once años para España, Santo Domingo, 6 de mayo de 1578, AGI, Indiferente General, 2059, N. 136.

84 Ibídem.

85 Ibídem; Registro para la Casa de Contratación, Armadas y Flota. Desde 21 de febrero de 1579 hasta 28 de enero de 1582, AGI, Indiferente General, 1969, L.23, f. 9.
} 
Armesto $^{86}$, favoreció la decisión de Elcano de elegir la ruta portuguesa y culminar así la circunnavegación.

En este contexto, las historias de los "otros participantes", la marinería, sobresalientes y grumetes, han sido eclipsadas en la historiografía oficial. Nuestra tarea ha consistido en exprimir hasta la medida de lo posible las fuentes para encontrar pistas que dieran solidez a la vida de un marinero, Ocasio Alonso, nacido en Bollullos, a camino entre Sevilla y los denominados "lugares colombinos". Las fuentes documentales nos han permitido entrar en su declaración, entre el 11 de abril y el 31 mayo de 1524 en las Juntas de Badajoz-Elvás, en la frontera hispano-lusa, donde se buscaba una solución diplomática a la posesión de las Molucas. También conocer la nao donde iba embarcado; el sueldo que disfrutaba como marinero, así como los adelantos proporcionados antes de levantar velas; premios otorgados durante el trayecto que nos permiten conocer los motivos de su asignación; las vicisitudes que les llevaron a ser retenido por los portugueses en las islas de Cabo Verde y su posterior liberación, pero también las entradas económicas que recibió de las deudas contraídas con otros compañeros de expedición en el transcurso de la misma, curiosamente todos fallecidos antes de terminar el periplo, y que percibió en Sevilla.

No disponemos de más datos biográficos directos de Ocasio Alonso. Desconocemos si se alistó en otras expediciones que con posterioridad pusieron rumbo a la Especiería, en las que repitieron algunos de los supervivientes de la de Magallanes, o a las Indias ${ }^{87}$. Tampoco sabemos la fecha de su muerte. Eso sí, la documentación histórica nos ha permitido localizar datos de su hijo y de su nieto, que nos demuestran la relación de ambos con la herencia que pudo dejar Ocasio Alonso en bienes en su pueblo de nacimiento, reclamados por Gerónimo de Espina, el nieto, nada más morir su padre.

Presentar los aspectos biográficos de Ocasio Alonso en el contexto donde se desarrollaron nos ha permitido revalorar su trayectoria en función del momento histórico en el que se desenvolvió el personaje. Un hecho singular como la circunnavegación del orbe tradicionalmente ha dado un puesto de honor a los "grandes hombres", a los "héroes", de los cuales sus "gestas" llenan anaqueles y estanterías. Sin embargo, acudir a los individuos ordinarios, como Ocasio Alonso, nos ha permitido revelar aspectos biográficos mediante el análisis intensivo de los documentos y de los hechos históricos.

\section{Fuentes}

Archivo General de Indias (AGI).

\footnotetext{
${ }^{86}$ FERNÁNDEZ-ARMESTO, Felipe. Los conquistadores del horizonte. Op. cit., p. 296.

${ }^{87}$ En 1525, antes del Tratado de Zaragoza, se organizó una nueva expedición a las Molucas siguiendo la misma ruta que inició Magallanes y finalizó Elcano. Ésta fue liderada por García Jofre de Loaisa. En la expedición fueron algunos de los antiguos integrantes de la que encabezó en 1520 el capitán portugués. Entre ellos, Juan Sebastián Elcano y Hernando de Bustamante, el compañero de Ocasio Alonso cuando en el Estrecho de Magallanes avistaron la ruta a seguir para dar con el Mar del Sur u Océano Pacífico; GARCÍA ABÁSOLO, Antonio. La primera exploración del Pacífico... Op. cit., p. 23.
} 
Contaduría.

Contratación.

Indiferente General.

Patronato.

\section{Bibliografía}

AGUIRRE ROJAS, C. A. La biografía como género historiográfico. Algunas reflexiones sobre sus posibilidades actuales. En: AGUIRRE ROJAS, C. A. Itinerarios de la historiografía del siglo XX. De los diferentes marxismos a los varios Annales. La Habana: Centro de Investigación y desarrollo de la cultura cubana Juan Marinello, 1999, pp. 98-119.

ANDAYA, L. Y. Los primeros contactos de los españoles con el mundo, de las Molucas en las Islas de las Especias. Revista Española del Pacífico. 1992, n. 2, año II, pp. 62-106.

BERNABEU, S. Magallanes: retrato de un hombre. En: YUSTE, C. y PINZÓN RíOS, G. (coords.). A 500 años del hallazgo del Pacífico. La presencia novohispana en el Mar del Sur. México: IIH-UNAM, 2016, pp. 21-54.

COMELLAS, J. L. La primera vuelta al mundo. Madrid: Ediciones Rialp, 2012.

DA FONSECA, L. A. The discoveries and the formation of the Atlantic Ocean: 14th century - 16th century. Lisbon: Comissão Nacional para as Comemorações dos Descobrimentos Portugueses, 1999.

DOSSE, F. El arte de la biografía. México: Universidad Iberoamericana, 2007.

FERNÁNDEZ-ARMESTO, F. Los conquistadores del horizonte. Una historia global de la exploración. Madrid: Ariel, 2012.

FERNÁNDEZ DE NAVARRETE, M. Colección de los viajes y descubrimientos que hicieron por mar los españoles desde fines del siglo XV. Madrid: Imprenta Nacional, 1837.

GARCÍA ABÁSOLO, A. La primera exploración del Pacífico y el asentamiento español en Filipinas. En: ELIZALDE PÉREZ GRUESO, M. D. Las relaciones entre España y Filipinas. Siglos XVI-XX. Madrid: CSIC, 2002, pp. 21-35.

HERRERA, A. de. Historia General de los hechos de los castellanos en las islas y tierra firme del Mar Oceáno. Década Segunda. Madrid: Imprenta Real, 1601.

HERRERA, A. de. Historia General de los hechos de los castellanos en las islas y tierra firme del Mar Oceáno. Década Tercera. Madrid: Imprenta Real, 1601.

HIDALGO NIETO, M. La cuestión hispano-portuguesa en torno a las islas Molucas. Revista de Indias. 1942, vol. III, n. 9, pp. 429-462. 
LOAIZA CANO, G. El recurso biográfico. Historia crítica. 2004, n. 24, pp. 221-238.

MARTINIC B., M. Una travesía memorable. Hallazgo y navegación del Estrecho de Magallanes (21 octubre-28 noviembre 1520). Chile: Talleres La Prensa Austral, 2016.

MEDINA, J. T. Colección de Documentos Inéditos para la Historia de Chile. Tomo I. Santiago de Chile: Imprenta Ercilla, 1888.

MEDINA, J. T. El descubrimiento del Océano Pacífico. Vasco Núñez de Balboa, Fernando de Magallanes y sus compañeros. Santiago de Chile: Imprenta Universitaria, 1920.

MEDINA, J. T. El descubrimiento del Océano Pacífico. Hernando de Magallanes y sus compañeros. Documentos. Santiago de Chile: Imprenta Elzeviriana, 1920.

MENA GARCÍA, C. El descubrimiento y la plataforma andaluza. La aportación onubense. En: Actas de las Jornadas de Historia sobre el Descubrimiento de América. Tomo II. Huelva: Universidad Internacional de Andalucía, 2011, pp. 4371.

MORALES PADRÓN, F. Teoría y Leyes de la conquista. Sevilla: Universidad de Sevilla, 2008.

MORENO MADRID, J. M. En torno a la expedición de Antonio de Abreu y Francico Serrão (1511-1521). En: Filipinas y el Pacífico: de los viajes por mar a los viajes por la red. Hacia la construcción de una herramienta de aprendizaje en línea [en línea]. Madrid: Proyecto Innova-Docentia-Convocatoria 2016-2017. No. de referencia: 219, Universidad Complutense de Madrid. Disponible en $<$ https://www.ucm.es/data/cont/docs/1035-2017-06-122.\%20EXPEDICI\%C3\%93N\%20ABREU-SERRAO.pdf>.

NUÑEZ DE LA FUENTE, José Manuel. Diario de Magallanes: el hombre que lo vio y anduvo todo. Madrid: Doce Calles, 2017.

PÉREZ-EMBID, F. Los descubrimientos del Atlántico y la rivalidad castellanoportuguesa hasta el Tratado de Tordesillas. Sevilla: EEHA-CSIC, 1948.

PÉREZ-MALLAÍNA, Pablo Emilio. Tierras por descubrir y ganar. En: LUCENA SALMORAL, Manuel (coord.). Historia de Iberoamérica. Tomo II, Historia Moderna. Madrid: Cátedra, 2002.

PIGAFETTA, A. Primer viaje en torno del Globo (versión castellana de Federico Ruiz Morcuende). Madrid: Calpe, 1922. 
PINO ABAD, M. El Tratado de Zaragoza de 22 de abril de 1529 como anticipo a la conquista de Filipinas. En: FERNÁNDEZ RODRÍGUEZ, M. (coord.). Guerra, derecho y política. Aproximaciones a una interacción inevitable. Valladolid: Asociación Veritas para el Estudio de la Historia, el Derecho y las Instituciones, 2014, pp. 25-44.

RUMEU DE ARMAS, A. El Tratado de Tordesillas. Madrid: Editorial Mapfre, 1992.

SÁNCHEZ GONZÁLEZ, D. M. Aspectos jurídicos de la negociación de las Molucas. Boletín de la Facultad de Derecho. 1993, n. 3, pp. 293-310.

SÁNCHEZ MARTÍNEZ, A. De la 'cartografía oficial' a la 'cartografía jurídica': la querella de las Molucas reconsiderada, 1479-1529. Nuevo Mundo Mundos Nuevos [en línea]. 2009. Disponible en $<$ http://nuevomundo.revues.org/index56899.html>. 